\title{
INFORMATION-ANALYTICAL SUPPORT OF REALIZATION OF CLUSTER POLICY IN THE REGIONS OF RUSSIA ${ }^{1}$
}

\author{
Alla E. Kalinina \\ Volgograd State University, Volgograd, Russian Federation \\ Elena A. Petrova \\ Volgograd State University, Volgograd, Russian Federation
}

\begin{abstract}
The article represents the results of elaborating the methodological toolset of a region's cluster policy. The proposed methodology is based on the main characteristics of the clusters (presence of competitive enterprises, availability of competitive advantages in the region for cluster development, geographical concentration and proximity, a wide range of participants and the presence of "critical mass", links and interactions between cluster members) characterizing them as complex economic structures. The creation of clusters implies a number of studies at the regional level, which, above all, relate to determining the competitive advantages of a region in a particular industry. Therefore, at the first stage of the assessment of the cluster potential of the region, the authors propose to conduct a comprehensive assessment of the competitive advantages of the regional sectors, which will make it possible to identify the vectors of development of the territory. The second stage involves a qualitative assessment of indicators of competitive stability in the region (factors of production, demand in the domestic market for the industry's products, competitive industries and suppliers of potential clusters). At the last stage, the composition of potential clusters and the nature of managerial influences of initiation and support of clusters by regional authorities are determined. In contrast to the existing methods for assessing the potential of a cluster, the approach implemented in this article makes it possible to identify not only promising territories from the point of view of clusterization of an industry, but also to identify possible participants of such a cluster, which is the most promising in forming regional cluster development programs in the regional economy. The article presents the approbation of the proposed methodology for the Volgograd region on the basis of statistical data for 2014-2016, identified industries and enterprises that can be clustered, which will ensure adequate support from regional authorities.

Key words: the competitiveness of the regional economy, cluster policy of the regional authorities, assessment and composition of potential clusters.

Citation. Kalinina A.E., Petrova E.A. Information-Analytical Support of Realization of Cluster Policy in the Regions of Russia. Vestnik Volgogradskogo gosudarstvennogo universiteta. Seriya 3, Ekonomika. Ekologiya [Science Journal of Volgograd State University. Global Economic System], 2018, vol. 20, no. 4, pp. 25-37. (in Russian). DOI: https://doi.org/10.15688/jvolsu3.2018.4.3
\end{abstract}

\section{ИНФОРМАЦИОННО-АНАЛИТИЧЕСКОЕ ОБЕСПЕЧЕНИЕ РЕАЛИЗАЦИИ КЛАСТЕРНОЙ ПОЛИТИКИ В РЕГИОНАХ РОССИИ ${ }^{1}$}

\author{
Алла Эдуардовна Калинина
}

Волгоградский государственный университет, г. Волгоград, Российская Федерация

\section{Елена Александровна Петрова}

Волгоградский государственный университет, г. Волгоград, Российская Федерация 
Аннотация. В статье представлены результаты разработки методического инструментария кластерной политики региональных органов власти. В основу предлагаемой методики положены основные характеристики кластеров (наличие конкурентных предприятий; наличие в регионе конкурентных преимуществ для развития кластера; географическая концентрация и близость; широкий набор участников и наличие «критической массы»; наличие связей и взаимодействия между участниками кластеров), характеризующие их как сложные экономические структуры. Создание кластеров предполагает проведение ряда исследований на региональном уровне, которые, прежде всего, касаются определения конкурентных преимуществ региона в той или иной отрасли производства. Поэтому на первом этапе оценки кластерного потенциала региона авторы предлагают проводить комплексную оценку конкурентных преимуществ отраслей региона, что позволит выявить векторы развития территории. Второй этап предполагает качественную оценку показателей конкурентной устойчивости региона (факторы производства, спрос на внутреннем рынке продукции отрасли, конкурентоспособные отрасли-поставщики потенциальных кластеров). На последнем этапе определяется состав потенциальных кластеров и характер управленческих воздействий инициирования и поддержки кластеров региональными властями. В отличие от существующих методов оценки потенциала кластера, реализуемый в данной статье подход позволяет выявлять не только перспективные с точки зрения кластеризации отрасли территории, но и определить возможных участников такого кластера, что является наиболее перспективным при формировании региональных программ развития кластеров в региональной экономики. В статье представлена апробация предлагаемой методики для Волгоградской области на основе статистических данных 2014-2016 гг, выделены отрасли и предприятия, которые могут быть объединены в кластер, что позволит обеспечить адекватную поддержку региональных властей.

Ключевые слова: конкурентоспособность экономики региона, кластерная политика региональных властей, оценка и состав потенциальных кластеров.

Цитирование. Калинина А. Э., Петрова Е. А. Информационно-аналитическое обеспечение реализации кластерной политики в регионах России // Вестник Волгоградского государственного университета. Серия 3 , Экономика. Экология. -2018. - Т. 20, № 4. - C. 25-37. - DOI: https://doi.org/10.15688/jvolsu3.2018.4.3

\section{Введение}

В последнее время появилось много публикаций, посвященных вопросам повышения конкурентоспособности территории, где одним из основных инструментов выступают кластеры. Кластеры в экономике региона представляют такую ее территориальную организацию, которая позволяет реализовать взаимовыгодные связи между предприятиями, принося дополнительную прибыль за счет снижения трансакционных издержек. Использование географической локализации организаций-партнеров, объединенных в кластер, а также поддержка со стороны органов государственной власти и научных организаций повышают эффективность таких объединений.

В мировой практике территориального управления показана успешная реализация этой концепции. Так, в США вопросы формирования и развития территориальных кластеров были отнесены к числу национальных приоритетов в докладе 2001 г. Совета по конкурентоспособности [12]. Причем положительный эффект достигается в тех отраслях экономики, которые не считались традиционны- ми в этом регионе. Таким примером может служить сформированный и успешно действующий кластер инновационных технологий в штате Канзас, традиционно считавшемся сельскохозяйственным [8]. В исследовании Института стратегии и конкурентоспособности (Institute for Strategy and Competitiveness, http:/www.isc.hbs.edu), проведенном по заказу губернатора штата и под руководством М. Портера, были предложены методики, позволяющие классифицировать и ранжировать кластеры предприятий на основе оценок изменения их основных характеристик за десятилетний период. Инструментом развития кластеров стала Канзасская Технологическая корпорация (Kansas Technology Enterprise Corporation, KTEC), учрежденная в 1987 году.

В Европе гораздо позднее стали использовать кластеры, как инструмент повышения конкурентоспособности экономики, они характеризуются более коротким сроком становления за счет использования накопленного опыта США. И в отличие от американского подхода, европейские кластеры являются связующим звеном для перехода инноваций и технологий между научной сферой и производством. 
Теоретическая идея использования кластеров в региональном развитии нашла свою реализацию в государственном управлении, показала возможность положительного воздействия в территориальном управлении [13].

Однако эта концепция имеет уже довольно длительную историю, первоначально осмысление возможности таких объединений предприятий-партнеров было замечено среди промышленных предприятий в конце XIX века. В своей монографии «Масштаб и сфера деятельности: движущие силы промышленного капитализма» А. Чандлер [11] на основе исследования деятельности крупных промышленных компаний в развитых странах (США, Германии и Великобритании) выделяет факторы, способствующие усилению роста, к которым относит масштаб производства, размер производства и уменьшение трансакционных издержек (за счет использования новых технологий, изменения рынка, появления новых и трансформации старых институтов государства и общества).

Впервые о кластерах в своей работе «Принципы экономики» [2] написал британский экономист Альфред Маршалл, который провел исследование промышленных районов Великобритании и выявил специфические особенности, позволившие работникам, имеющим схожие трудовые навыки, объединяться в замкнутые промышленные образования (узлы Маршалла). Он назвал такие территории индустриальными агломерациями (industrial agglomerations), а также доказал наличие дополнительных конкурентных преимуществ у этих объединений, к которым отнес «пул специализированных рабочих, доступ к различным высокоспециализированным поставщикам продуктов и услуг, быстрый обмен информацией».

Развитию теории промышленных кластеров послужила публикация в 1990 г. монографии профессора Гарвардского университета Майкла Портера «Конкурентные преимущества стран» («The Competitive Advantage of Nations») [14], в которой идея конкурентных преимуществ была распросранена на национальную конкурентоспособность. М. Портер обосновывает свою концепцию конкурентоспособности страны через наличие в ее экономике не просто успешных компаний или отраслей, но кластеров, которые он определяет че- рез географическую локализацию взаимосвязанных компаний, партнеров-поставщиков не только материалов и сырья, но и услуг, необходимых для организации работы (например, различных консультационных агентств, торговых компаний, научных организаций). Главным в этих объединениях является способность компаний, объединенных в кластер, оптимально использовать доступные внутренние ресурсы. Кроме того, им обоснована система характеристик международного конкурентного преимущества национальных экономик, названная «конкурентный ромб» или «алмаз» [15].

Новая парадигма территориального управления включает в себя основным элементом теорию кластеров, которая утверждает, что в современных экономических условиях успешная хозяйственная деятельность возможна только при выстраивании связей внутри объединения вокруг крупной компании, причем эти связи поддерживают материальные, информационные, финансовые потоки между элементами кластера. Механические объединения отдельных производителей не дают положительного результата, настройка этих связей требует использования более тонких механизмов управления $[16 ; 18]$.

Обобщение теоретических и практических подходов к описанию структуры кластеров позволяет выделить следующие составные элементы, как правило, входящие в состав кластеров, различных по своему назначению: корневая компания (core firm, возмозможно 2-3 основных предприятия, являющихся ядром кластера); фирмы-поставщики, в том числе поставщики услуг (сырье, материалы, комплектующие, оборудование, машины, сервисное обслуживание); сбытовые общества и торговые компании; представительства трудящихся (профсоюзы); финансовые институты (инвесторы); политические институты и местные органы власти; организации, поставляющие человеческие ресурсы (образовательные организации высшего и среднего специального образования, организации повышения и переподготовки специалистов); научноисследовательские и аналитические центры.

Согласно исследованию [4] наиболее успешные кластеры в регионе характеризуются следующими показателями: присутствие в экономике предприятий, способных выдерживать 
конкуренцию в определенной отрасли; наличие условий для формирования и развития кластера; географическая локализация достаточного количества участников, наличие условий для выстраивания взаимодействия между участниками. Причем первые три характеристики могут рассматриваться как необходимые для реализации кластерной политики.

В качестве условий для формирования и развития кластеров выступают: выгодное географическое положение; доступ к сырью; трудовые ресурсы высокого профессионального уровня, наличие компаний, являющихся поставщиками комплектующих и связанных услуг, специализированных учебных заведений и образовательных программ, наличие высокой научно-исследовательской активности специализированных организаций, необходимой инфраструктуры и другие факторы.

Как отмечалось выше, кластеры по сравнению с традиционными формами организации экономической деятельности имеют ряд преимуществ:

- территориальная концентрация компаний (поставщики, производители) и связанных с ними организаций (образовательные заведения, органы государственного управления, инфраструктурные компании), действующих в определенной сфере и взаимодополняющих друг друга, взаимодействующих друг с другом в рамках единой цепочки создания прибавочной стоимости, позволяет оптимально организовать это взаимодействие и распространить свое положительное влияние на ближайшее окружение (поставщиков, потребителей и конкурентов), что, в свою очередь, оказывает влияние на дальнейший рост конкурентоспособности данного кластера;

- развитие гибких сетевых структур (инновационных кластеров), создаваемых на основе многосторонних соглашений и объединяющих вузы, научные организации, предприятия, инновационные фирмы;

- управление технологическими центрами таких кластерных образований осуществляется компетентными сервисными компаниями, заинтересованными в скорейшей коммерциализации проектов, в формировании портфеля заказных НИОКР для каждого кластера, в генерации новых проектов и, наконец, в трансфере технологий.
Положительным моментом в деятельности кластера также является то, что внутри кластера между большинством его участников снижается или снимается полностью конкуренция. Так как кластеры объединяют в своем составе и научно-исследовательские организации, то это позволяет сократить внедрение инноваций в производство, скорректировать направления научного исследования и опытно-конструкторских разработок, оптимально настроить производственный процесс. Взаимодействие участников внутри кластера имеет свои специфические особенности, которые приобретают вид корпоративных интересов и позволяют интегрировать в кластер новых участников независимо от их размера. Компаниям среднего и малого бизнеса легче приспособиться к изменению конъюнктуры рынка, национальные и транснациональные компании за счет аккумуляции крупных финансовых ресурсов позволяют выстраивать долгосрочные стратегии.

Таким образом, создание кластеров в региональной экономике способствует достижению конкретного хозяйственного эффекта и усиливает конкурентные преимущества отдельных компаний, а следовательно, кластера в целом. Кластеры эффективнее, чем отрасли, охватывают важные связи, обеспечивая взаимодополняемость отраслей, способствуя развитию технологий, навыков и распространению информации, значимой для осуществления бизнеса [7].

\section{Материалы и результаты исследования}

В России, несмотря на активную деятельность региональных властей по формированию кластерных структур, лишь относительно небольшая часть проектов развития кластеров достигла стадии практической реализации, хотя целесообразность создания кластера для регионов Российской Федерации уже давно неоднократно отмечалась разными исследователями $[1 ; 9 ; 10]$. Россия сегодня пытается использовать преимущества кластерного подхода в решении задач развития экономики регионов, однако она еще не преодолела начальный этап - адаптации категории «кластерная политика» к специфике российских условий взаимодействия государственной власти, науки и образования, бизнеса и общества [17]. 
В 2008 г. Министерством экономического развития России была принята Концепция кластерной политики в стране и разработаны «Методические рекомендации по реализации кластерной политики в субъектах Российской Федерации» [3], в которых определены основные направления содействия развитию кластеров, реализуемые органами государственной власти и местного самоуправления; система мероприятий по реализации кластерной политики; механизмы финансовой поддержки реализации кластерной политики на федеральном уровне.

Однако стратегия развития каждого конкретного кластера должна разрабатываться и реализовываться на региональном уровне, при активном участии органов местного самоуправления. В этой связи наиболее актуальным становится развитие методического инструментария процессов формирования кластеров в регионах. В основу предлагаемой методики положены основные характеристики кластеров (наличие конкурентных предприятий; наличие в регионе конкурентных преимуществ для развития кластера; географическая концентрация и близость; широкий набор участников и наличие «критической массы»; наличие связей и взаимодействия между участниками кластеров), характеризующие их как сложные экономические структуры.

Создание кластеров предполагает проведение ряда исследований на региональном уровне, которые, прежде всего, касаются определения конкурентных преимуществ региона в той или иной отрасли производства. Поэтому на первом этапе оценки кластерного потенциала региона авторы предлагают проводить комплексную оценку конкурентных преимуществ отраслей региона, что позволит выявить векторы развития территории.

Анализ конкурентных преимуществ региона целесообразно проводить в три этапа:

- проведение оценок конкурентной устойчивости отраслей экономики региона, определение рыночной конъюнктуры региональных рынков;

- проведение оценок условий конкурентной устойчивости отраслей экономики региона, что предполагает качественный анализ ресурсов производства;

- проведение оценок кластерного потенциала экономики региона, выявление видов экономической деятельности, в которых потенциально возможно реализовывать кластерную политику.

Оценки проводятся по доступной статистической информации, публикуемой Росстатом РФ, в качестве таких индикаторов можно использовать индексы финансового состояния предприятий, инвестиционной активности, индекс корпоративного развития, коэффициент экономической активности населения региона, индекс ресурсной обеспеченности предприятий, коэффициент локализации отрасли на территории региона, коэффициент душевого производства и коэффициент специализации региона на данной отрасли. Формулы расчета и интерпретация полученных значений представлены в таблице 1.

Принимаемое значение коэффициентами единицы и больше означает, что соответствующий вид экономической деятельности (ВЭД) возможно охарактеризовать как ВЭД рыночной специализации, и в этом секторе экономики региона возможно создание кластера. Анализ изменения коэффициента локализации в динамике позволяет принять управленческое решение об организации кластера, положительная динамика показателя характеризует рост уже существующего кластера, отрицательная - говорит о необходимости воздействия на такой кластер (например, пересмотр ассортимента выпускаемой продукции, модернизации производства).

Следующий этап анализа коэффициентов включает ранжирование отраслей, что является основой для включения отраслей более высокого ранга в дальнейшие расчеты, однако окончательное решение об исключении отрасли из рассмотрения принимается на основе экспертных оценок.

Следующий этап целесообразно начинать с определения качественных показателей, которые дадут возможность определить ресурсную базу формируемого кластера. Доступные условия развития кластера в экономике региона группируются по следующим направлениям:

- оценка спроса на локальном рынке выделенных отраслей;

- выделение предприятий региона, способных выступать конкурентоспособными поставщиками в организуемом кластере. 
Расчетные показатели конкурентных преимуществ отраслей региона

\begin{tabular}{|c|c|c|}
\hline Наименование показателя & Формула расчета & Интерпретация результата \\
\hline $\begin{array}{l}\text { Индекс финансового состоя- } \\
\text { ния предприятий региона }\end{array}$ & $I_{\phi \mathrm{c}}=\Pi_{\text {mmp. }} / \Pi_{\text {oб }}$ & $\begin{array}{l}\text { Рассчитывается как отношение числа прибыльных } \\
\text { промышленных организаций к общему количеству } \\
\text { предприятий данного региона }\end{array}$ \\
\hline $\begin{array}{l}\text { Индекс инвестиционной ак- } \\
\text { тивности }\end{array}$ & $I_{\mathrm{UHE}}=V_{\mathrm{oxr}} / V_{\mathrm{oka}}$ & $\begin{array}{l}\text { Отношение объема инвестиций в основной капитал } \\
\text { предприятий отдельной отрасли к объему инвести- } \\
\text { ций в основной капитал всех отраслей региона }\end{array}$ \\
\hline $\begin{array}{l}\text { Коэффициент экономической } \\
\text { активности населения }\end{array}$ & $K_{\mathrm{gax}}=\mathrm{P}_{\mathrm{sMa} / \mathrm{P}}$ & $\begin{array}{l}\text { Как отношение численности экономически актив- } \\
\text { ного населения в общей численности населения } \\
\text { региона (на определенную дату) }\end{array}$ \\
\hline $\begin{array}{l}\text { Индекс корпоративного разви- } \\
\text { тия }\end{array}$ & $I_{\text {mopn }}=\Pi_{\pi} / \Pi_{o \sigma}$ & $\begin{array}{l}\text { Доля предприятий отрасли, приходящихся на } 10 \\
\text { тыс. чел. населения территории }\end{array}$ \\
\hline $\begin{array}{l}\text { Коэффициент локализации от- } \\
\text { расли }\end{array}$ & $\mathrm{K}_{\mathrm{rT}}=$ & $\begin{array}{l}\text { Отношение удельного веса отрасли в структуре } \\
\text { производства региона к удельному весу той же от- } \\
\text { расли в стране }\end{array}$ \\
\hline $\begin{array}{l}\text { Коэффициент душевого про- } \\
\text { изводства }\end{array}$ & $\mathrm{K}_{\mathrm{I}}=$ & $\begin{array}{l}\text { Отношение удельного веса отрасли региона в со- } \\
\text { ответствующей структуре отрасли страны к удель- } \\
\text { ному весу населения региона в населении страны }\end{array}$ \\
\hline Индекс специализации & $\overline{\Pi_{p} / \Pi_{c} * 100}$ & $\begin{array}{l}\text { Отношение удельного веса отрасли региона в объ- } \\
\text { еме выпуска продукции отрасли страны к удель- } \\
\text { ному весу хозяйства региона в хозяйстве страны. } \\
\text { Индекс уровня специализации имеет то же содер- } \\
\text { жание, что и коэффициент локализации, но вычис- } \\
\text { ляется другим способом }\end{array}$ \\
\hline
\end{tabular}

Примечание. Составлено авторами.

Основой для такого качественного анализа может послужить экспертный опрос, где в качестве экспертов могут выступать руководители предприятий региона.

Для факторов производства проводится качественная оценка наличия и доступности природных, материальных, трудовых, инфраструктурных и прочих факторов производства по двузначному критерию (доступны/недоступны).

Спрос на рынке для продукции отрасли оценивается с помощью количественных и качественных показателей: доли продукции отрасли, реализуемой в пределах России, в постсоветских республиках, за рубежом и их динамика в последние 3-5 лет.

Оценка наличия в экономике региона компаний, которые могут выступать в качестве поставщиков-партнеров кластерооразующих организаций, является решающей при определении возможности формирования кластера и условий его устойчивого развития.
Количественными показателями выступают доли поставщиков отрасли, расположенных в пределах региона, в пределах федерального округа, в России, в постсоветских республиках, за рубежом, и динамика их поставок в последние 3-5 лет.

Полученные оценки позволяют сформировать первичные группы отраслей, которые в результате укрупненной группировки объединяются в три группы:

- отрасли с высоким потенциалом существования кластера, нуждающиеся в информационной поддержке и минимальном управляющем воздействии;

- отрасли, в которых возможно создание кластеров при целенаправленных длительных управляющих воздействиях;

- отрасли, в которых создание кластеров требует значительных издержек, несопоставимых с ожидаемым эффектом.

Проведение следующего этапа целесообразно для первых двух групп отраслей. 
Для отраслей, отобранных на первых этапах анализа, необходимо определить степень влияния потенциальных кластеров на конкурентоспобность региона. На этом же этапе определяется и состав возможных кластеров по следующим направлениям: институциональная организация кластеров, внутренняя мотивация инициирования и поддержания кластеров, сравнительная конкурентоспособность участников кластера, стратегический потенциал кластеров.

Институциональная организация кластеров предполагает отбор группы предприятий, для которых возможно объединение в кластер. Для этих предприятий необходимо проверить наличие следующих характеристик:

- структурированность (наличие устойчивой организационной структуры); стников);

- устойчивость (постоянный состав уча-

- наблюдаемость (открытость и прозрачность основных показателей деятельности предприятия для государственной и муниципальной статистики).

Внутренняя мотивация инициирования и поддержания кластеров. Для формирования жизнеспособных кластеров необходимо также учесть мотивацию участников. Основанием для выделения групп предприятий могут выступать следующие мотивы:

- производство однородной продукции;

- однородность основных покупателей крупных государственных или полугосударственных структур;

- обеспечение мобильности труда и капитала внутри кластера;

- другие мотивы.

Сравнительная конкурентная сила участников кластера.

Фактором, определяющим конкурентную силу кластера, может быть конкурентная сила его отдельных участников. Здесь возможны следующие модели:

- кластер с примерно одинаковой конкурентной силой участников;

- кластер, где конкурентная сила центральных участников значительно превосходит конкурентную силу остальных;

- кластер, в котором конкурентная сила периферийных участников намного превосходит конкурентную силу центральных;
- кластер, состоящий из конкурентно слабых участников.

Поэтому в качестве критериев оценки стратегического потенциала кластеров могут использоваться следующие показатели:

- темп роста продукции отраслей, в которых заняты центральные предприятия кластера в сравнении с темпом роста экономики в целом (отраслевой рост);

- темп роста продукции кластера в сравнении с темпом роста отрасли в целом (кластерный рост);

- доля продукции отраслевого кластера в валовом региональном продукте.

Таким образом, предлагаемая методика предполагает расчет следующих показателей для выявления потенциала формирования кластеров в регионе (см. рисунок).

Авторами проведена апробация предлагаемой методики для Волгоградской области за 2014-2016 годы.

Расчетные показатели конкурентных преимуществ отраслей региона представлены в таблице 2. Так как государственная статистика публикует результаты социально-экономического развития регионов в разрезе видов экономической деятельности, то поэтому в таблице группировка осуществляется в соответствии с этими показателями.

На основе проведенного анализа конкурентной устойчивости региона имеем расчетные коэффициенты больше или равные единице в отраслях «сельское хозяйство», «обрабатывающие производства» и «производство и распределение электроэнергии». Следовательно, данные отрасли могут выступать как отрасли рыночной специализации, и в них либо уже существуют кластеры или их создание является наиболее возможным. Однако, обратив внимание на динамику коэффициентов локализации, в отрасли «производство и распределение электроэнергии» констатируем уменьшение коэффициента с течением времени, что говорит о необходимости модернизации производства или о неперспективности кластера в будущем. В отраслях «сельское хозяйство» и «обрабатывающие производства» коэффициент увеличивается во времени, что говорит о возможных дальнейших перспективах роста производства и кластеров. 


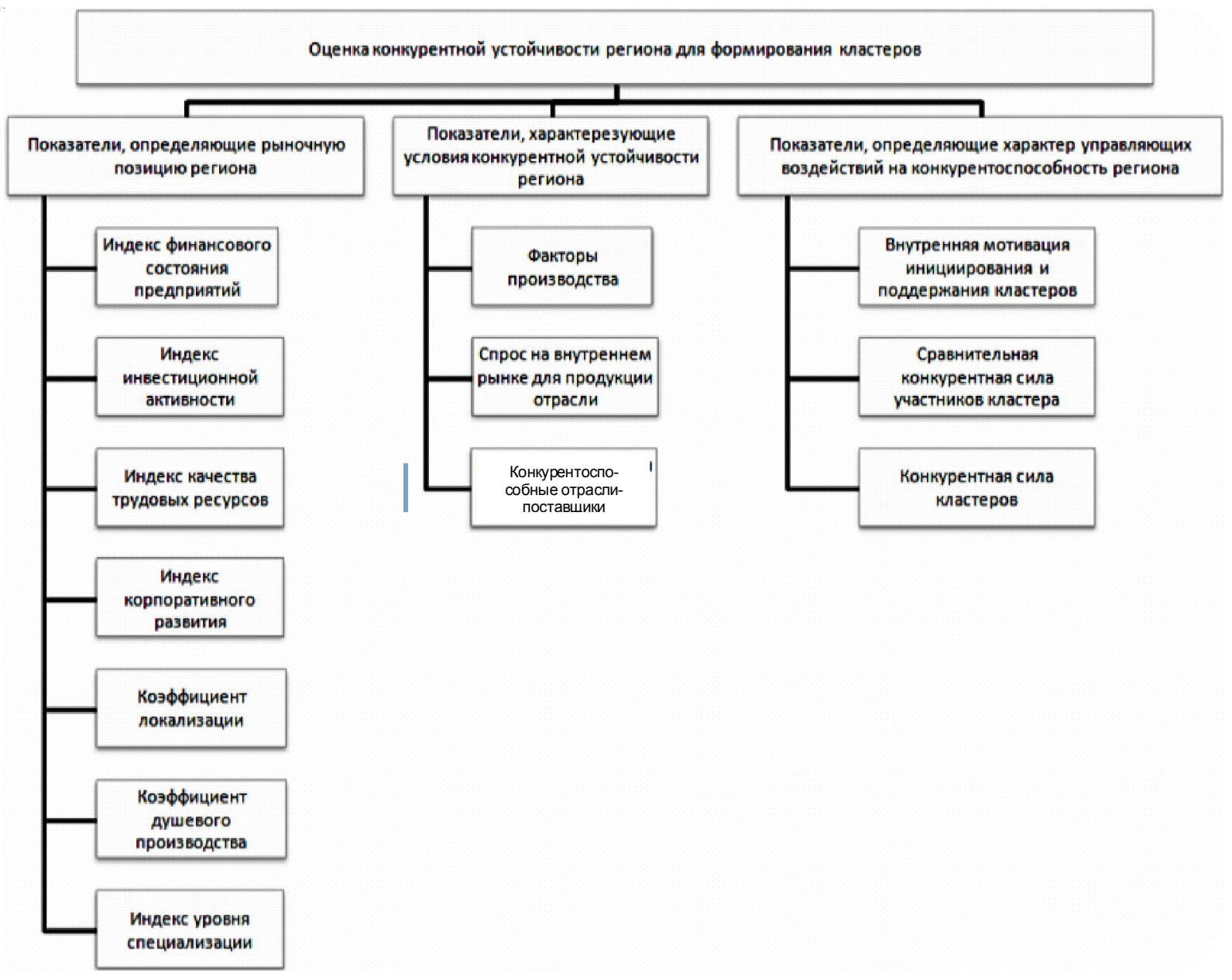

Рисунок. Показатели оценки потенциала кластера региона

Примечание. Составлено авторами.

Таблица 2

Расчетные показатели конкурентных преимуществ отраслей региона для Волгоградской области

\begin{tabular}{|l|c|c|c|}
\hline \multicolumn{3}{|c|}{ Наименование показателей } & \multicolumn{3}{|c|}{ Период } \\
\cline { 2 - 4 } Добыча полезных ископаемых & 2014 & 2015 & 2016 \\
\hline \multicolumn{3}{|c|}{} \\
\hline Индекс финансового состояния предприятий региона & 0,002 & 0,0008 & 0,001 \\
\hline Индекс инвестиционной активности & 0,02 & 0,01 & 0,01 \\
\hline Коэффициент экономической активности населения & 0,002 & 0,002 & 0,002 \\
\hline Индекс корпоративного развития & 0,0115 & 0,0129 & 0,0136 \\
\hline Коэффициент локализации отрасли & 0,7 & 0,5 & 0,4 \\
\hline Коэффициент душевого производства & 0,3 & 0,3 & 0,3 \\
\hline Индекс специализации Обрабатывающие производства & 0,54 & 0,5 & 0,38 \\
\hline \multicolumn{4}{|c|}{} \\
\hline Индекс финансового состояния предприятий региона & 0,05 & 0,03 & 0,05 \\
\hline Индекс инвестиционной активности & 0,2 & 0,23 & 0,13 \\
\hline Коэффициент экономической активности населения & 0,09 & 0,08 & 0,07 \\
\hline Индекс корпоративного развития & 0,37 & 0,39 & 0,41 \\
\hline Коэффициент локализации отрасли & 1,5 & 1,36 & 1,52 \\
\hline Коэффициент душевого производства & 0,88 & 0,88 & 1,05 \\
\hline Индекс специализации & 1,45 & 1,3 & 1,46 \\
\hline
\end{tabular}




\section{Расчетные показатели конкурентных преимуществ отраслей региона} для Волгоградской области

\begin{tabular}{|c|c|c|c|}
\hline \multirow{2}{*}{ Наименование показателей } & \multicolumn{3}{|c|}{ Период } \\
\hline & 2014 & 2015 & 2016 \\
\hline \multicolumn{4}{|l|}{ Сельское хозяйство } \\
\hline Индекс финансового состояния предприятий региона & 0,06 & 0,05 & 0,04 \\
\hline Индекс инвестиционной активности & 0,05 & 0,035 & 0,03 \\
\hline Коэффициент экономической активности населения & 0,08 & 0,07 & 0,07 \\
\hline Индекс корпоративного развития & 0,42 & 0,39 & 0,35 \\
\hline Коэффициент локализации отрасли & 1,8 & 1,9 & 2,3 \\
\hline Коэффициент душевого производства & 1,1 & 1,38 & 1,6 \\
\hline Индекс специализации & 1,8 & 2 & 2,3 \\
\hline \multicolumn{4}{|c|}{ Производство и распределение электроэнергии } \\
\hline Индекс финансового состояния предприятий региона & 0,003 & 0,003 & 0,004 \\
\hline Индекс инвестиционной активности & 0,07 & 0,06 & 0,05 \\
\hline Коэффициент экономической активности населения & 0,01 & 0,01 & 0,01 \\
\hline Индекс корпоративного развития & 0,041 & 0,047 & 0,051 \\
\hline Коэффициент локализации отрасли & 1,2 & 1,1 & 0,8 \\
\hline Коэффициент душевого производства & 0,72 & 0,72 & 0,5 \\
\hline Индекс специализации & 1,18 & 1,08 & 0,76 \\
\hline \multicolumn{4}{|l|}{$\begin{array}{r}\text { Строительство } \\
\end{array}$} \\
\hline Индекс финансового состояния предприятий региона & 0,07 & 0,08 & 0,05 \\
\hline Индекс инвестиционной активности & 0,03 & 0,02 & 0,02 \\
\hline Коэффициент экономической активности населения & 0,03 & 0,03 & 0,03 \\
\hline Индекс корпоративного развития & 0,43 & 0,51 & 0,52 \\
\hline Коэффициент локализации отрасли & 0,6 & 0,8 & 0,7 \\
\hline Коэффициент душевого производства & 0,3 & 0,5 & 0,5 \\
\hline Индекс специализации & 0,54 & 0,75 & 0,69 \\
\hline \multicolumn{4}{|l|}{ Транспорт и связь } \\
\hline Индекс финансового состояния предприятий региона & 0,04 & 0,009 & 0,03 \\
\hline Индекс инвестиционной активности & 0,2 & 0,24 & 0,21 \\
\hline Коэффициент экономической активности населения & 0,03 & 0,03 & 0,04 \\
\hline Индекс корпоративного развития & 0,26 & 0,3 & 0,32 \\
\hline Коэффициент локализации отрасли & 0,84 & 0,82 & 0,7 \\
\hline Коэффициент душевого производства & 0,5 & 0,5 & 0,5 \\
\hline Индекс специализации & 0,8 & 0,75 & 0,69 \\
\hline
\end{tabular}

Примечание. Рассчитано авторами.

Для дальнейшего анализа рассматриваются все отрасли, вне зависимости от полученных коэффициентов. На данном этапе рано делать выводы, так как полученные результаты дополнятся результатами качественного анализа и тогда уже можно говорить о полной экономической ситуации в регионе, о наиболее развитых и перспективных отраслях, в которых есть вероятность создания и развития конкурентноспособных кластеров.

Качественная оценка факторов производства, наличия и доступности природных, трудовых и прочих факторов производства проводилась в ходе экспертного опроса руково- дителей предприятий Волгоградской области. Последующее обобщение полученных экспертных оценок позволяет сделать вывод о доступности водных, минерально-сырьевых (полезные ископаемые), энергетических (наличие на территории области Волжской ГЭС), земельных ресурсов. Кроме того, эксперты отметили доступность и достаточную квалификацию трудовых ресурсов во всех видах экономической деятельности региона. Это подтверждается наличием в регионе заведений высшего профессионального образования (12 организаций высшего образования и научных организаций на начало учебного года 2016/2017), среднего профессионального образования (73 заве- 
дения на начало учебного года 2016/2017) и образовательных заведений, осуществляющих подготовку квалифицированных рабочих (33 заведения в 2015 году). Таким образом, Волгоградская область в достаточной степени обеспечена профессиональными учебными учреждениями, которые выпускают специалистов для конкретных отраслей производства. Большая часть населения занята в промышленных отраслях, что так же может быть предпосылкой для формирования кластеров [6, с. $373,376,414]$.

Если проводить анализ такого показателя, как «Инвестиции в основной капитал по видам экономической деятельности» за 2015 и 2016 гг., то надо отметить общее снижение этого показателя по всем ВЭД почти на 18952 млн руб., однако в таких видах деятельности, как сельское хозяйство (в 2016 г. показатель увеличился на 1 638,2 млн руб.), производство и распределение электроэнергии, газа и воды (в 2016 г. показатель увеличился на 5 642,1 млн руб.), строительство (в 2016 г. показатель увеличился на 288,6 млн руб.) и оптовая и розничная торговля, ремонт автотранспортных средств, мотоциклов, бытовых изделий и предметов личного пользования (в 2016 г. показатель увеличился на 843 млн руб.) произошло увеличение инвестиций $[5$, с. 1261 $1262 ; 6$, с. 635-636].

Спрос на рынках можно оценить как продукцию отрасли, в постсоветских республиках, за рубежом и их динамика в последние 3-5 лет. Данные по товарной структуре экспорта и импорта по Волгоградской области за период 2015-2016 гг. представлены в таблице 3. Анализ представленных данных также показывает общее снижение как экспорта, так и импорта по всем товарным группам, причем наибольшее снижение (почти в 2 раза) показали продовольственные товары и сельскохозяйственное сырье и продукция топливно-энергетического комплекса.

Основные страны-партнеры по экспорту: Италия, Украина, Иран, Турция, Казахстан, Узбекистан, Нидерланды.

Основные экспортирующие отрасли и отрасли, наиболее привлекательные для инвесторов: «Добыча полезных ископаемых» и «Обрабатывающие производства».

Проведенный анализ показал, что именно эти отрасли экономики могут выступить кластерообразующими и имеющими наибольший потенциал для создания перспективных кластеров. Поэтому целесообразно перечислить крупные предприятия Волгоградской области, которые представлены в следующих отраслях.

Топливно-энергетический комплекс: - ООО «ЛУКОЙЛ-Волгограднефтегаз».

Металлургический комплекс:

- ЗАО «ВМЗ «Красный Октябрь»;

- ОАО «Волжский трубный завод».

Производство машин, транспортных средств и оборудования:

- ОАО «Тракторная компания ВГТЗ»;

- ОАО «Волжский подшипниковый завод»;

- ОАО «Волгограднефтемаш»;

- ОАО «Волгоградэнерго».

Химическая промышленность: работка»;

- ООО «ЛУКОЙЛ-Волгограднефтепере-

- ОАО «Сибур-Волжский»;

- ОАО «Каустик»;

- ОАО «Волжский оргсинтез»;

- ОАО «Волтайр-Пром».

Товарная структура экспорта и импорта в 2015-2016 гг. (млн долл. США) по Волгоградской области

\begin{tabular}{|c|c|c|c|c|c|c|c|c|c|c|c|c|}
\hline \multicolumn{13}{|c|}{ Товарная структура экспорта и импорта } \\
\hline \multirow[t]{2}{*}{ Период } & \multicolumn{2}{|c|}{$\begin{array}{c}\text { Продовольст- } \\
\text { венные товары } \\
\text { и сельскохозяй- } \\
\text { ственное сырье } \\
\text { (группы } 1-24 \text { ) }\end{array}$} & \multicolumn{2}{|c|}{$\begin{array}{c}\text { Продукция топ- } \\
\text { ливно-энергети- } \\
\text { ческого ком- } \\
\text { плекса } \\
\text { (группа 27) }\end{array}$} & \multicolumn{2}{|c|}{$\begin{array}{l}\text { Продукция хи- } \\
\text { мической про- } \\
\text { мышленности, } \\
\text { каучук } \\
\text { (группы 28-40) }\end{array}$} & \multicolumn{2}{|c|}{$\begin{array}{c}\text { Древесина } \\
\text { и целлюлозно- } \\
\text { бумажные } \\
\text { изделия } \\
\text { (группы 44-49) }\end{array}$} & \multicolumn{2}{|c|}{$\begin{array}{c}\text { Металлы и из- } \\
\text { делия из них } \\
\text { (группы 72-83) }\end{array}$} & \multicolumn{2}{|c|}{$\begin{array}{c}\text { Машины, обо- } \\
\text { рудование и } \\
\text { транспортные } \\
\text { средства } \\
\text { (группы 84-90) }\end{array}$} \\
\hline & ЭКспорт & импорт & экспорт & импорт & экспорт & импорт & экспорт & импорт & экспорт & импорт & Экспорт & импорт \\
\hline 2015 г. & 272,5 & 80,7 & 954,7 & 16,5 & 281,8 & 125,7 & \begin{tabular}{l|}
7,7 \\
\end{tabular} & 36,2 & 466,2 & 323,6 & 29,4 & 399,4 \\
\hline 2016 г. & 137,8 & 60,5 & 503,6 & 6,2 & 257,1 & 122,9 & 4,0 & 23,6 & 352,2 & 168,5 & 21,6 & 236,7 \\
\hline
\end{tabular}

Примечание. Составлено авторами по: [5, с. 1311; 6, с. 1385]. 
Транспортный комплекс:

- Волгоградское отделение Приволжской железной дороги - филиала ОАО «Российские железные дороги»;

- ОАО «Международный аэропорт Волгоград».

\section{Пишевая промышленность:}

- ЗАО «Народное предприятие «Конфил»;

- ОАО «Урюпинский масло-экстракционный завод»;

- ОАО «Волгомясомолторг»;

- ОАО «Маслодельно-сыродельный комбинат “Михайловский”»;

- ОАО «Городищенский комбинат хлебопродуктов»; Волга».

- ООО «Табачная фабрика Реемтсма-

Конкурентоспособные отрасли-поставщики или другие сопутствующие отрасли в Волгоградской области отбирались на основе данных Территориального органа Федеральной службы государственной статистики по Волгоградской области. Количественными показателями выступают доли поставщиков отрасли, расположенных в пределах региона (табл. 4).

Приведенные в таблице 4 данные показывают, что на территории Волгоградского региона наибольшую долю занимают поставщики отрасли «Обрабатывающие производства» и вспомогательные производства отрасли «Строительство».

Полученные в ходе апробации методики оценки позволяют сформировать первичные группы отраслей, которые в результате группировки объединяются в три укрупненные группы:
- отрасли с высоким потенциалом существования кластера, нуждающиеся в информационной поддержке и минимальном управляющем воздействии. Для Волгоградского региона такими отраслями являются «Обрабатывающие производства» и «Сельское хозяйство, охота и лесное хозяйство, рыболовство, рыбоводство»;

- отрасли, в которых возможно создание кластеров при целенаправленных длительных управляющих воздействиях. В данном регионе такими отраслями могут являться «Строительство» и «Транспорт»;

- отрасли, в которых создание кластеров требует значительных издержек, несопоставимых с ожидаемым эффектом. Отраслями с низким потенциалом для кластеризации в Волгоградской области являются: «Производство и распределение электроэнергии, воды, газа», «Добыча полезных ископаемых».

В ходе исследования была выявлена потенциально возможная кластерообразующая отрасль - «Обрабатывающие производства». Наиболее перспективным на территории Волгоградской области представляется организация химического кластера, имеющего следующую структуру: центр кластера - основные ведущие предприятия отрасли, в качестве них могут выступить: ОАО «Волжский оргсинтез», ОАО «Каустик», ОАО «Сибур-Волжский», ОАО «Волтайр-Пром».

В роли поставщиков инноваций, а также подготовки высококвалифицированных кадров для данного кластера выступает Волгоградский государственный технический университет.

\section{Доля предприятий-поставщиков по видам экономической деятельности}

в Волгоградской области в 2016 г.

\begin{tabular}{|l|c|}
\hline \multicolumn{1}{|c|}{ Отрасль } & $\begin{array}{c}\text { Доля поставщиков } \\
\text { отрасли в регионе, \% }\end{array}$ \\
\hline $\begin{array}{l}\text { Сельское хозяйство, охота и лесное } \\
\text { хозяйство, рыболовство, рыбоводство }\end{array}$ & 10,0 \\
\hline Добыча полезных ископаемых & 5,9 \\
\hline Обрабатывающие производства & 27,0 \\
\hline $\begin{array}{l}\text { Производство и распределение элек- } \\
\text { троэнергии, газа и воды }\end{array}$ & 6,0 \\
\hline Строительство & 47,0 \\
\hline Транспорт и связь & 3,1 \\
\hline
\end{tabular}

Примечание. Составлено авторами. 


\section{Заключение}

Вследствие слабого развития в российской экономике отдельных рыночных институтов особая роль в формировании кластеров как возможных точек роста региональной экономики принадлежит государственным структурам. В первую очередь необходимо сформировать институциональную среду кластерной политики как на федеральном, так и на региональном уровнях, а также благоприятную экономическую среду для функционирования сетевых структур посредством механизмов государственно-частного партнерства.

Для российской экономики, возможно, является интересным не только создание «внутренних» кластеров как устойчивых схем развития регионов, но и построение международных кластеров (в приграничных территориях, например, с Финляндией и Китаем), обеспечивающих жизнеспособность кластеров посредством интенсивного обмена ресурсами, технологиями (как производственными, так и управленческими), посредством ноу-хау, реализации оригинальных бизнес-моделей, создания единого информационного пространства и т. п.

Для реализации кластерной политики на региональном уровне авторы предлагают методический инструментарий, основанный на количественном анализе как конкурентных преимуществ отраслей региональной экономики, так и на качественном анализе существующих внутри- и межрегиональных связей отдельных производственных, инфраструктрурных и научно-исследовательских организаций и компаний. Данный подход позволяет выявлять не только перспективные с точки зрения кластеризации отрасли территории, но и определить возможных участников такого кластера, что является наиболее перспективным при формировании региональных программ развития кластеров в региональной экономике.

\section{ПРИМЕЧАНИЕ}

1 Исследование выполнено при финансовой поддержке РФФИ и Волгоградской области в рамках научного проекта «Оценка эффективности реализации кластерной политики социально-экономического развития региона», проект № 18-410340020 p_a.

\section{СПИСОК ЛИТЕРАТУРЫ}

1. Клейнер, Г. Б. Синтез стратегии кластера на основе системно-интеграционной теории / Г. Б. Клейнер, Р. М. Качалов, Н. Б. Нагрудная // Наука - Образование -Инновации. -2008. - № 7. - С. 9-39.

2. Маршалл, А. Принципы экономической науки / А. Маршалл. - М. : Прогресс, 1993. - 594 с.

3. Методические рекомендации по реализации кластерной политики в субъектах Российской Федерации : угв. Минэкономразвития РФ 26.12.2008 № 20615ак/д19). - Электрон. текстовые дан. - Режим доступа: http://www.economy.samregion.ru/klaster_rossia/ npa_klaster_ros/metod_klaster_ros. - Загл. с экрана.

4. Прайс, В. Кластерная политика / В. Прайс. М. : Дело, 1996. - 341 с.

5. Регионы России. Социально-экономические показатели. 2016 : стат. сб. - М. : Росстат, 2016. - 1326 с.

6. Регионы России. Социально-экономические показатели. 2017 : стат. сб. - М. : Росстат, 2017.-1402 с.

7. Третьяк, В. П. Кластеры предприятий / В. П. Третьяк. - Изд. 3-е, перераб. и доп. - М. : [б. и.], 2011.-390 с.

8. Третьяк, В. П. Кластеры предприятий / В. П. Третьяк. - М. : Август Борг, 2006. -219 с.

9. Филиппов, П. Кластеры конкурентоспособности / П. Филиппов // Эксперт Северо-Запад. 2003. - № 43 (152). - Электрон. текстовые дан. - Режим доступа: http://www.expert.ru/economy/2003. Загл. с экрана.

10. Шерешева, М. Ю. Проблемы создания инновационных кластеров в регионах России / М. Ю. Шерешева // Наука - Образование - Инновации. - 2008. - № 7. - С. 214-230.

11. Chandler, A. D., Jr. Scale and Scope: The Dynamics of Industrial Capitalism / A. D. Chandler, Jr. ; with the assistance of T. Hikino. - Belknap Press : Cambridge, MA, 1990.

12. Council on Competitiveness, Monitor Company, and M. Porter. Clusters of Innovation : National Report. - Washington, 2001.

13. Ketels, Ch. European Clusters. Structural Change in Europe. 3: Innovative City and Business Regions / Ch. Ketels. - Hagbarth Publications, 2004.

14. Porter, M. E. The Competitive Advantage of Nations / M. E. Porter. - N. Y. : The Free Press, 1990.

15. Porter, M. E. The Economic Performance of Regions / M. E. Porter // Regional Studies. - 2003. Vol. 37, № 6-7. - P. 549-678.

16. Rabelotti, R. Recovery of a Mexican Cluster: Devaluation Bonanza or Collective Efciency? / R. Rabelotti // World Development. - 1995. - Vol. 27, № 9. - P. 1571-1585.

17. Tarakanov, V. Methodological Toolset of Regional Authority Bodies' Cluster Policy / V. Tarakanov, A. Kalinina, E. Petrova // Russia and 
the European Union. Development and Perspectives. Contributions to Economics. - 2017. - P. 55-63.

18. Villarreal Lizzarraga, C. L. Contribution au pilotage des projets partags par des PME en groupement base sur la gestion des isqué / C. L.Villarreal Lizzarraga. - Toulouse, 2006.

\section{REFERENCES}

1. Kleyner G.B., Kachalov R.M., Nagrudnaya N.B. Sintez strategii klastera na osnove sistemnointegratsionnoy teorii [A cluster's strategy synthesis, basing on a system-integration theory]. Nauka Obrazovaniye-Innovatsii, 2008, no. 7, pp. 9-39.

2. Marshall A. Printsipy ekonomicheskoy nauki [Principles of economics]. Moscow, Progress Publ., $1993.594 \mathrm{p}$.

3. Metodicheskiye rekomendatsii po realizatsii klasternoy politiki $v$ subyektakh Rossiyskoy Federatsii: utv. Minekonomrazvitiya RF 26.12.2008 № 20615-ak/d19) (Methodical recommendations about implementation of a cluster policy in territorial subjects of the Russian Federation]. URL: http:// www.economy.samregion.ru/klaster_rossia/npa klaster_ros/metod_klaster_ros.

4. Prays V. Klasternaya politika [Cluster policy], Moscow, Delo Publ., 1996. 341 p.

5. Regiony Rossii. Sotsialno-ekonomicheskiye pokazateli. 2016: stat. sb. [Regions of Russia. Socioeconomic indicators]. Moscow, Rosstat Publ., 2016. 1326 p.

6. Regiony Rossii. Sotsialno-ekonomicheskiye pokazateli. 2017: stat. sb. [Regions of Russia. Socioeconomic indicators]. Moscow, Rosstat Publ., 2017. 1402 p.

7. Tretiak V.P. Klastery predpriyatiy [Enterprise Clusters]. Izd. 3-e, pererab. idop. Moscow, [b.i.], 2011. 390 p.
8. Tretiak V.P. Klastery predpriyatiy [Enterprise Clusters], Moscow, Avgust Borg Publ., 2006. 219 p.

9. Filippov P. Klastery konkurentosposobnosti [Competitiveness Clusters]. Ekspert Severo-Zapad, 2003, no. 43 (152). URL: http://www.expert.ru/economy/ 2003.

10. Sheresheva M.Yu. Problemy sozdaniya innovatsionnykh klasterov $\mathrm{v}$ regionakh Rossii [Problems of creating innovation clusters in the regions of Russia]. Nauka - Obrazovaniye Innovatsii, 2008, no. 7, pp. 214-230.

11. Chandler A.D., Jr. Scale and Scope: The Dynamics of Industrial Capitalism. Belknap Press, Cambridge, MA, 1990.

12. Council on Competitiveness, Monitor Company, and M. Porter. Clusters of Innovation: National Report. Washington, 2001.

13. Ketels Ch. European Clusters. Structural Change in Europe. 3: Innovative City and Business Regions. Hagbarth Publications, 2004.

14. Porter M.E. The Competitive Advantage of Nations. New York, The Free Press, 1990.

15. Porter M.E. The Economic Performance of Regions. Regional Studies, 2003, vol. 37, no. 6-7, pp. 549-678.

16. Rabelotti R. Recovery of a Mexican Cluster: Devaluation Bonanza or Collective Efciency? World Development, 1995, vol. 27, no. 9, pp. 1571-1585.

17. Tarakanov V., Kalinina A., Petrova E. Methodological Toolset of Regional Authority Bodies' Cluster Policy. Russia and the European Union. Development and Perspectives. Contributions to Economics, 2017, pp. 55-63.

18. Villarreal Lizzarraga C. L. Contribution au pilotage des projets partag?s par des PME en groupement base sur la gestion des isqué. Toulouse, 2006.

\section{Information about the Authors}

Alla E. Kalinina, Doctor of Economics, Professor, First Vice Rector, Volgograd State University, Prosp. Universitetsky, 100, Volgograd, Russian Federation, allakalinina@yandex.ru, https:/orcid.org/0000-0002-1354-2015

Elena A. Petrova, Doctor of Economics, Professor, Head of the Department of Applied Informatics and Mathematical Methods in Economics, Volgograd State University, Prosp. Universitetsky, 100, Volgograd, Russian Federation, ea_petrova@mail.ru, https://orcid.org/0000-0002-6417-9498

\section{Информация об авторах}

Алла Эдуардовна Калинина, доктор экономических наук, профессор, первый проректор, Волгоградский государственный университет, просп. Университетский, 100 г. Волгоград, Российская Федерация, allakalinina@yandex.ru, https://orcid.org/0000-0002-1354-2015

Елена Александровна Петрова, доктор экономических наук, профессор, заведующая кафедрой прикладной информатики и математических методов в экономике, Волгоградский государственный университет, просп. Университетский, 100 г. Волгоград, Российская Федерация, ea_petrova@mail.ru, https://orcid.org/0000-0002-6417-9498 